\title{
Coaching by design: exploring a new approach to faculty development in a competency-based medical education curriculum
}

This article was published in the following Dove Press journal:

Advances in Medical Education and Practice

Christine J Orr'

Ranil R Sonnadara ${ }^{2}$

'Discipline of Medicine, Memorial University of Newfoundland, St. John's Newfoundland and Labrador, Canada;

${ }^{2}$ Department of Surgery, McMaster

University, Hamilton, ON, Canada
Correspondence: Christine J Orr Division of Endocrinology, Health Sciences Centre, Rm. 4325A, St. John's, NL AIB 3V6, Canada

Tel + I 7098646525

Fax +I 7097776273

Email Christine.orr@medportal.ca

\begin{abstract}
As curricula move from a time-based system to a competency-based medical education system, faculty development will be required. Faculty will be asked to engage in the observation, assessment and feedback of tasks in the form of educational coaching. Faculty development in coaching is necessary, as the processes and tools for coaching learners toward competence are evolving with a novel assessment system. Here, we provide a scoping review of coaching in medical education. Techniques and content that could be included in the curricular design of faculty development programming for coaching (faculty as coach) are discussed based on current educational theory. A novel model of coaching for faculty (faculty as coachee) has been developed and is described by the authors. Its use is proposed for continuing professional development.
\end{abstract}

Keywords: faculty development, coaching, competence based medical education, coaching medical education, faculty coaching

\section{Introduction}

Faculty development programming has been essential in building, sustaining and renewing academic medical communities. ${ }^{1}$ Its importance is amplified in the current climate of national, mandated curricular transformation. Curricula are moving from a time-based system, in which duration of experience leads to achievement, to a competency-based medical education (CBME) system, where clinical observation of behaviors and achievement of task-specific milestones lead to the establishment of competence. ${ }^{2}$ In CBME, the goal is to provide individual tailored instruction by faculty to each learner on specific tasks. The Royal College of Physicians and Surgeons of Canada have specified faculty are to observe learners and engage in a feedback model aligned with the principles of coaching; assuming the role they describe as a "feedback-coach."3 Although coaching is successful in other spheres, it has yet to be widely adopted in medical education teaching. Sargent and colleagues reported that when asked to coach, "facilitators felt unfamiliar with the role. Feedback recipients reported finding the coaching helpful, whereas facilitators generally reported that it was a skill that did not come naturally to them." 4 Despite this unfamiliarity, CBME mandates faculty act as feedbackcoaches. As more programs begin the transition to $\mathrm{CBME}$, training faculty in coaching will become increasingly important. The purpose of this paper is to review current literature on faculty development, coaching as an educational tool, and to 
suggest successful strategies for faculty coach development. It will discuss techniques and content that could be included in the curricular design of faculty development programming for coaching (faculty as coach). A novel model of coaching for faculty (faculty as coachee) has been developed by the authors. Its use is proposed for continuing professional development.

\section{Methods}

This scoping review was conducted to explore existing evidence on coaching as an educational tool in medical education and as part of CBME, which specific coaching techniques have been effective, and to identify opportunities and gaps in faculty development. The findings were used to discuss the potential utility of coaching as a tool for faculty development and to discover what factors in faculty coaching may be most effective. These findings were used to develop an original model of coaching for faculty development.

A systematic search of four databases was conducted: Ovid MEDLINE, PubMed, EMBASE, and Cochrane using keywords related to coaching in health professions education and faculty development were used. Keywords included coach OR coaching AND faculty development OR continuing professional development AND efficacy OR outcome OR success AND medical education AND competency based medical education OR CBME. In addition to keyword search, reviewed article citations were examined and explored for further sources. This source examination continued in new papers until selected materials were no longer relevant or novel. Additional gray literature sources included the Royal College of Physicians and Surgeons of Canada website on Competence by Design, and individual program websites for Canadian Universities faculty development programs, texts on motor learning and learning theory as well as individual coaching program sites as referenced by journal articles discovered in the database search. All searches concluded on March 12, 2018.

Studies were included where they addressed coaching interventions and outcomes in educational literature including health professions education, faculty development, music, sport and motor learning. Faculty development literature in medicine was included where program development, coaching, benefits or challenges were described. Faculty development papers were excluded if they did not describe outcomes for faculty or students, were not written in English, were opinions, letters to the editor, were not available in full-text format or were redundant.
The PRISMA reporting guideline was followed. Each study was reviewed for inclusion and exclusion criteria. Studies were organized and reported in this paper in applicable sections: a need for faculty development, coaching in medical education, coaching and learning efficacy, learning theories for faculty development activities, how to coach, available materials for faculty development in coaching. A new program for faculty development was developed using the information gathered to address gaps in currently identified programming and opportunities for growth.

\section{Background Need for faculty development}

Whereas teaching is giving systemic information to a person about a subject, ${ }^{5}$ coaching is training a student in specific aspects of their art. ${ }^{5}$ Teaching focuses on imparting information and may occur regardless of observation or goal setting; it may not be specific to an individual learner. Coaching is focused on the observation, guidance and skill development of an individual student. 6,7 "While teaching and mentoring are more instructional and directive, coaching is facilitative and guides the recipient in identifying their own needs and goals and in developing a realistic plan." ${ }^{8}$ Faculty development in coaching is necessary, as the processes and tools for coaching learners toward competence are evolving with a novel assessment system. Currently, faculty provide learners with access to clinical settings and the opportunity to assess patients. Following this, role modeling via a faculty-patient interaction occurs with the learner as an observer. CBME endeavors to change the current apprenticeship framework within medical education, the "See one, do one, teach one" model. Instead, Entrustable Professional Activities (EPAs) are used to establish specific achievements. EPAs are discipline-specific tasks that learners must complete with direct or indirect observation. Each EPA is composed of smaller milestones, or task components, which can be individually evaluated. By demonstrating the ability to perform composite milestones, and eventually the EPA as a whole, a learner will be considered competent in a single skill. CBME achievement exists when learners complete all discipline-specific EPAs. $^{2}$ Without observation and specific feedback, learners cannot achieve EPAs. EPA specificity in CBME is perfectly aligned with the observation, assessment and feedback which are foundational to coaching. ${ }^{2}$ EPA 
achievement must occur on a foundation of medical knowledge and education and represents achievement of a workplace-based skill. Faculty development in efficient observation and effective coaching are paramount to the success of CBME. ${ }^{9-13}$ "The implementation of CBME requires teachers and evaluators to gain a new understanding of the theory and practice of education, one that is different from that demanded of them by content and time based systems." ${ }^{14}$ Faculty development can lead to the acquisition of new teaching skills, new ways of thinking about the student-teacher relationship and increased commitment to educational scholarship. ${ }^{15}$ Strategies to facilitate role transition and clarification of desired coaching behaviors may be beneficial. A recent national needs assessment of Obstetrics and Gynecology faculty found that CBME is viewed positively by faculty, but is not well understood. It identified a need for improved understanding of assessment schema and techniques for feedback. ${ }^{16}$ A needs assessment at the University of Saskatchewan found faculty were not: using feedback, incorporating learning objectives into teaching, familiar with clinical teaching skills or well equipped to teach students in difficulty. ${ }^{17}$ Following the implementation of CBME at Queen's University faculty noted "the importance of faculty development has been critical. In retrospect, given that our preceptors really are our instruments for competency-based assessment, we would have benefited from a process that built our preceptors' expertise as teachers and assessors." ${ }^{18}$ Favreau et $\mathrm{al}^{19}$ identified content areas for faculty development programs to foster coaching skills. These areas were improving faculty ability to lead meaningful conversations with learners about individual performance, identification and training in behaviors which impact learner reception and acceptance of feedback and promotion of stronger learner-supervisor relationships. Faculty development for coaching is necessary; however, best practices for training faculty coaches remain uncertain. ${ }^{20,21}$

\section{Coaching in medical education}

In medical education, the role of the coach is relatively novel. ${ }^{22}$ Gawande $^{23}$ introduced the concept of medical coaching and proposed that established, practicing physicians would benefit from peer observation and feedback. Medical coaching has recently been introduced experimentally in undergraduate ${ }^{20}$ and postgraduate residency programs. ${ }^{24,25}$ Its use has emerged as a strategy for implementing individualized education, allowing faculty to guide the performance, competency and career progression of an individual learner. ${ }^{22}$ Within coaching cultures of sport, music and medicine, development of a strong relationship between teacher and learner were found to be essential for the facilitation of meaningful feedback delivery. ${ }^{26} \mathrm{~A}$ cooperative style of coaching, which emphasizes shared goals, has been reported as the most efficacious for adult learners in sport. ${ }^{27}$ Coaching in medicine is "a longitudinal helping relationship between coach and apprentice that provides continuing feedback on and assistance with improving performance." 28 It fits into the co-operative learning paradigm and has been shown to improve knowledge acquisition, problem-solving and cognitive growth. ${ }^{29}$

In academic contexts, coaching is at times used synonymously with mentoring; however, many authors argue coaching is a distinct concept. ${ }^{30,31}$ Coaching and mentoring both use questioning, enabling and guiding. ${ }^{30}$ Mentorship assumes advising, counseling and supporting in a way that coaching does not and typically represents a long-term relationship. The duration of a coaching relationship can be varied. ${ }^{30}$ Deiorio et $\mathrm{a}^{22}$ note that unlike mentors, "coaches do not offer advice or therapy to learners they are coaching. Rather, after reviewing objective data on performance, coaches employ methods that help the learners gain insights into their own assumptions... and help identify specific actions needed to achieve a desired result." The role of coach is collaborative with focus on goal setting, developing solutions, goal attainment, selfdirected learning, ${ }^{32}$ development of learner-centric novel approaches, ${ }^{33}$ increased self-awareness and personal responsibility of the coachee. ${ }^{3}$ Importantly, the coach facilitates goal attainment by following the agenda of the coachee, who then implements coach suggestions to achieve goals. ${ }^{32}$ In sports, two styles of coaching prevail; the autocratic style in which the coach dictates the behavior of the coachee and the democratic style in which the coach and coachee communicate and share in decisionmaking. ${ }^{34}$ Medical education coaching literature supports communication and shared goal setting in keeping with a democratic style of coaching. The coach must be respected so that both positive and negative feedback are adopted by the student.

\section{Coaching and learning}

Much of what is known regarding the efficacy of coaching stems from literature in motor learning and sports. Augmented feedback, that is supplemental feedback following a task, involving knowledge of performance (KP) 
and knowledge of results (KR), are among the most important variables for motor learning. ${ }^{35} \mathrm{KR}$ has been shown to have greater impact on task performance with increased availability and usefulness of the feedback given. The importance of the quality of feedback has also been proven essential to task outcomes in KP studies. It has been established that those provided with specific instruction as verbal coaching on how to improve performance demonstrate greatest success in learning, ${ }^{35}$ and that positive feedback may be motivational toward further learning. ${ }^{36}$ Augmented feedback leads to motor learning by providing information about what went wrong with previous tasks and by specifying ways to improve tasks. ${ }^{35}$

The importance of specific instruction for performance success is well documented in sports coaching literature. In 2004, Gallimore and Tharp ${ }^{37}$ reviewed hours of sports coaching and documented 2,326 instances of feedback which were then coded by type. Comments were $6.6 \%$ praise, $6.9 \%$ reproach and greater than $75 \%$ neutral instruction. They discovered that instructive feedback is significantly more successful than either praise or reproach; a finding consistent with other sports coaching literature. In medical education, feedback is often delivered using models such as the sandwich method ${ }^{38}$ in which feedback is given in a format of praise-substance-praise. Therefore, medical educators are delivering roughly $66 \%$ praise, for every $33 \%$ of critical instructional feedback. Although this practice is not universal, feedback delivered to learners has been criticized as vague, general and not trainee specific. ${ }^{33}$ Identified issues with current feedback strategies have included: feedback arriving "too late" at the end of a rotation, when the opportunity for practice is over, feedback that is too general, such that residents cannot specifically identify or remedy a behavior and feedback with unclear behavioral anchors. ${ }^{39}$ Helpful feedback was noted to be timely, behavior-specific, focused and educational. ${ }^{39}$ This data suggest that current practices of high praise, low specificity feedback are not useful for learners. A coaching strategy as demonstrated by athletic coaches, with a high percentage of clear behavioral instruction, may result in improved outcomes.

A literature review encompassing 21 studies on coaching efficacy for medical learners found positive outcomes in areas of well-being and resilience, decision-making, teamwork, reflective practice and technical skill acquisition. ${ }^{33}$ Coaching has been equally useful for faculty members. It has been suggested that receiving coaching as part of continuing professional development can inform practice change and may improve patient outcomes. ${ }^{8}$ Within the R2C2 Facilitated Feedback Model ${ }^{4}$ "coaching for performance change," was trialed. This coaching was described by participating physicians as an activity central to enabling them to change. Transfer of skills from educational session to classroom increased from $15-20 \%$ following workshop training, to $95 \%$ following coaching. ${ }^{29}$

The efficacy of coaching may be influenced by the approach to leadership used by the coach. Use of transactional and transformational leadership behaviors have been shown to positively affect coaching outcomes. ${ }^{40}$ Transactional leadership focuses on external motivation to lead to improved performance and depends on rules, standards and corrective actions. Transformational leadership focuses on the intrinsic needs of the follower and uses a vision to achieve commitment, gain respect and foster trust. ${ }^{41}$ When used concurrently, these leadership styles have resulted in effective coaching outcomes. Successful strategies include reliance on coach for structure (transactional) with individual consideration with commitment from coach and coachee (transformational). ${ }^{40}$ Grover and Furnham $^{42}$ reported that use of initial dominant coach behavior was predictive of goal attainment, consistent with a transactional leadership approach.

Available data suggest coaching improves performance, well-being, self-regulation, ${ }^{43}$ self-efficacy, ${ }^{42}$ resilience ${ }^{44-46}$ and goal attainment. ${ }^{47}$ Literature from the fields of business, ${ }^{43,48}$ motor learning, ${ }^{35,49}$ athletics, ${ }^{50,51}$ nursing $^{46,52}$ and medical education ${ }^{20,24,33,53-55}$. conclude that coaching is effective.

\section{Faculty development for the coaching role}

\section{Theories of learning}

Thus far, it has been established that coaching is effective, will be employed in novel CBME curricula and that faculty development in this domain is necessary. However, participation in faculty development is voluntary. Challenges identified in the uptake of these activities include teaching falling in priority compared to patient care, administration and research commitments, limited training as clinical educators ${ }^{56}$ and the complex setting of university hospitals with increased competing demands for attention. ${ }^{57}$ Therefore, faculty development programming must be relevant, accessible, desirable, feasible and be seen to be valued by the institution. These programs should be designed to promote and maintain the interest of 
faculty and should adhere to principles of adult learning and theories of behavior change to increase the uptake of proposed interventions.

The andragogical model, also known as the adult learning theory, outlines principles of adult learning that can be applied to planning and conducting adult learning programs. ${ }^{58}$ It contains six components: the need to know, learners' self-concept, learners' life experience, readiness to learn, orientation to learning and motivation. ${ }^{58}$ Adhering to these principles may influence the success of faculty development activities and should be considered in novel faculty development program design. Parts of this andragogy are already included in common learning activities. For example, clinical cases in rounds are both problem-centered and directly relevant to medical practice. Use of relevant problem-centered learning could be expanded beyond clinical cases. One novel approach may be inclusion of real anonymized feedback from student evaluations in sample exercises to contextualize and highlight challenges for faculty participants. This type of material may draw on the previous experience of the learners. Focusing on errors or negative feedback may also promote discussion of points that are still unfamiliar. ${ }^{59}$ Similarly, simple exercises, such as asking faculty to reflect on a recent clinical interaction with a learner, can contextualize concepts and aid with comprehension of coaching material. The importance of selfdirected learning and internal motivation to learn are crucial to both andragogy and self-determination theory.

Self-determination theory posits an individual's motivation to participate in learning is driven by three factors: a sense of relatedness, autonomy and competence. ${ }^{60}$ To create an environment of relatedness, faculty development activities could be completed using division-wide events such as workshops or rounds. Within these group events, interacting within breakout sessions, or group participation activities (eg, voting for the best answer with polling software) may be effective at increasing participation and engagement. Networking opportunities are among the most valued aspects of faculty development programs, ${ }^{61}$ contribute to the development of collegial networks ${ }^{62}$ and strengthen the academic community. ${ }^{63}$

Sense of autonomy may be challenged by the mandated nature of the CMBE curricular change; when local stakeholders are not present, individual faculty may be resistant to change. Autonomy may be promoted by inviting faculty to become a CBD champion ${ }^{2}$ who promotes CBD uptake within an individual division or institution. As the population of stakeholders grows, so too may buy-in, individual responsibility and sense of autonomy. This type of increased buy-in is described as essential in theories of organizational change. ${ }^{64}$

Autonomy is present in the voluntary nature of faculty development activities. This can be increased by seeking faculty feedback on content via needs assessments or surveys. The entire session could be learner driven, where learners attend to ask questions about their coaching practice and discuss answers with the group and an expert. $^{59}$

The sense of competence, or of being able to perform a task, ${ }^{60}$ is challenging to foster. When faculty are asked, or have begun to engage in teaching behaviors without training, ${ }^{56}$ this sense of competence may be diminished, potentially lowering motivation to participate in educational efforts. Sense of competence can be increased by aligning tasks with abilities and providing affirmative feedback and instruction. ${ }^{60}$

A sample faculty development activity for coaching, consistent with self-determination theory, would be an active learning activity wherein small groups complete an exercise with which they have reasonable skill (sense of competence), such as observing a video of a medical student taking a history. Faculty would be asked to independently break down the history into important component parts and record these findings to assess the demonstrated history-taking competence by the medical student (autonomy, constructivism). Group members could compare their responses following the video (relatedness). Thereafter, increased motivation to complete a second, more advanced task is expected (competence).

This exemplar task includes the use of deliberate practice. Ericsson et al ${ }^{65}$ reported that the peak performance in a given domain is not achieved by routine experience, but by deliberate practice. They found even highly experienced persons can improve performance by the use of deliberate practice. Practice can increase self-efficacy. ${ }^{66}$

Social cognitive theory (SCT) identifies social factors which lead to knowledge acquisition, behavior change and motivation. It is relevant to understand the successes or failures of a coaching approach and can be employed to increase the likelihood of guiding learner behaviors ${ }^{66}$ Within SCT, self-efficacy is described as the most important characteristic in determining whether behavioral change will occur. Self-efficacy is increased by achievement, positive reinforcement and belief that outcomes result from task engagement. ${ }^{66}$ Designing programs utilizing theories of behavior change leads to more effective 
program outcomes. ${ }^{67}$ Multiple internal factors influence behavior change including an individual's knowledge, motivation or self-efficacy. External factors that affect behavior change may be teaching environment, or social factors, including sense of relatedness, perception of importance and the credibility of the program or instructor. $^{4}$

\section{Current faculty development coaching programs}

Faculty development programs are available for those interested in improving coaching skills. The "Dr. Coach" framework, for example, was created and trialed in pediatric residency programs at Dartmouth College ${ }^{68}$ The focus of Dr. Coach is to emphasize deliberate practice of coaching skills. It endorses creation of a coaching environment, deconstructing skill expertise using milestones, observing learner behavior and eliciting a learner self-assessment. The Dr. Coach model has been primarily delivered via faculty development workshops and seminars ${ }^{68}$ The Royal College of Physicians and Surgeons of Canada ${ }^{2}$ have a myriad of faculty development resources available for the transition to CBME. There is one webinar video on bedside coaching available. ${ }^{69}$ Some individual universities, ${ }^{70-73}$ offer at least one online video lecture on coaching topics. While these online resources contain excellent content and are accessible, self-directed and autonomous; they do not offer the opportunity for deliberate practice, provide a sense of relatedness, contain learner-driven content, increase learner motivation, selfefficacy or concepts supporting behavior change and are limited in individual feedback, duration and scope. No longitudinal faculty development coaching program for medical education could be identified. More resource development is required in order to create a new national paradigm for clinical teaching.

\section{Coaching program development- What faculty development activities may be successful?}

Although available programs are invaluable to faculty who actively seek out education on coaching, it has been established that all faculty may benefit from instruction to succeed with the impending paradigm shift from assessor to coach. ${ }^{19}$ In 2017 , there were 55,508 reported faculty members within Canada's 17 Faculties of Medicine, instructing 16,334 residents. ${ }^{74}$ Available opportunities for faculty development in coaching may be insufficient to meet current needs. Individual programs must seek solutions to meet faculty development needs accompanying the transition to CBME at a local level. Although a single faculty development curriculum will not work in every context, certain principles may be used for successful program design. Development of programs that promote ongoing opportunities for practice, troubleshooting, feedback and support is required. Creation of faculty development programs commonly includes four stages: pre-planning, planning, delivery and follow up. ${ }^{75}$ Here, strategies which are theoretically effective for faculty development and which can be applied to pre-planning for coaching development are described.

Faculty development initiatives for coaching programs must address motivation for participation. Adult learning theory suggests that motivation is influenced by the subjective relevance of the content to the learner and may be increased by learning that is self-directed and autonomous. ${ }^{58}$ Consequently, use of individual learning goals is viewed favorably. ${ }^{59}$ Reconciling formal program design and participant autonomy may be difficult. A proposed solution is creating a system of participant inclusion into the program design itself; for example, inclusion of an informal meeting with peer coaches or experts would allow for potential feedback and support. This type of activity promotes relatedness by creating an environment of shared inquiry. Disciplines may consider adding a "view-point" or discussion period into existing rounds. This could create a culture where CBME teaching techniques are viewed with importance, and familiarize those who may not seek out faculty development for CBME with the domain of medical education coaching.

Gazelle et $\mathrm{al}^{44}$ have noted the importance of reflection on action for coaching and goal setting. "By exercising authority over their thoughts and beliefs, people can move from reactivity to purposeful response. Enhanced selfreflection and self-awareness are foundational to the coaching enterprise." Exercises to enhance reflection could include evaluation of content or describing activities. Faculty learners could be provided with a case vignette and asked to record the type of coaching phrases or actions they might apply. The next step of the vignette would provide a prepared example of coaching that occurred. Learners would then be asked to evaluate the coaching in the example. By reflecting on desired behaviors and actively examining example coaching practice, reflection on action is present, which increases awareness 
of desirable skills. ${ }^{44}$ Faculty learners may compare the evaluation of the example coaching to their own suggested coaching in part one, to gain insight into their own coaching reaction. This type of exercise should allow learners to explore their unperceived needs.

In this example, deliberate practice is included. Deliberate practice will improve skill acquisition ${ }^{65}$ and is one aspect missing from currently available faculty development tools in coaching via online webinars. To facilitate deliberate practice, online videos using interactive exercises or avatars could be applied. Within these sessions, activities should begin with simpler challenges to improve learner sense of competence and self-efficacy before building to more challenging tasks. In workshops, coaching practice could occur with rotation through sample stations. Practice coaching for multiple skills, such as communication, professionalism or procedures, could occur in a single day.

Education technologies can promote accessibility and dissemination of coaching materials, increase awareness of coaching efforts and increase relatedness. The success of this type of rhizomatic learning ${ }^{76}$ is clear in the FOAM (or free open access meducation) movement. This movement disseminates medical information easily in an online community of practice. It leads to free distribution, promotion and sharing of educational materials ${ }^{77}$ by identifying them with the hashtag \#FOAMed. With increasing digital literacy, use of online resources and tools can quickly facilitate the understanding and uptake of a novel intervention. Online resources in faculty development ${ }^{78}$ and coaching already exist. ${ }^{69}$ Sharing these to create a community of coaching practice is feasible and may increase motivation, relatedness and self-efficacy. A simple starting point might be to create an online CBME coaching reflection space, where coaches from different institutions or disciplines can connect to discuss ideas, troubleshoot or post articles in the style of a living library. Although online communities of practice for medical education, coaching and reflection have not been reported in the literature, e-portfolio use in rehabilitation professionals, ${ }^{79}$ in undergraduate medical education $^{80}$ and occupational therapists ${ }^{81}$ have been successful in promoting reflective practice and engagement in CPD.

Apprenticeship has been employed in medical education for hundreds of years. ${ }^{82}$ It is commonly employed in sports coaching and is strongly supported as essential to coach development. ${ }^{83}$ Iyasere et $\mathrm{al}^{84}$ notes that the practice of medicine is built on the apprenticeship model. Cognitive apprenticeship has been used to teach coaching in business and leadership programs. ${ }^{85}$ Cognitive apprenticeship is used to teach mental models via expert demonstration. The apprentice applies the modeled behavior to a novel situation, following which they reflect on both the modeled and attempted activities. $^{85}$ In medical education coaching, an expert coach could verbalize which aspects of student behavior they are focused on, or how they are facilitating reflection for a student in front of an apprentice. This modeling and task explanation may reduce cognitive load, or the capacity used by working memory, ${ }^{86}$ for apprentices who try to observe, assess, plan and communicate. Cognitive load is reduced by use of worked examples for novice learners. This is particularly important for conditions with high cognitive load from multiple element interactivity. ${ }^{87}$ By including a coaching apprenticeship, there is an opportunity to improve learning, skill development and feedback for an apprentice. Where positive outcomes from coaching are observed, increased learner self-efficacy and buy-in may develop.

As faculty engage in novel coaching behavior, they may wish to provide feedback on how coaching techniques work in practice and whether attempted programs are useful or successful. Allowing participants to contribute to program evaluation is necessary for success, and may add to learner satisfaction in keeping with the principle of autonomy.

\section{Practical coaching content-}

\section{What content should be taught to faculty coaches?}

Coaching literature has clearly identified behaviors and strategies which are efficacious for successful coaching. Content on how to coach should be inclusive of these ideas and principles and may introduce coaching models or frameworks. Desirable coach behaviors include strong communication, decision-making and instruction, ${ }^{88}$ inspiring academic and professional growth, investing time in students, providing direction, ${ }^{89}$ having knowledge in the students' area of interest and being flexible in supervision strategies. ${ }^{30}$ Multiple authors have emphasized the importance of communication, feedback quality, rapport and direct instruction as the key behaviors that lead to coaching efficacy. ${ }^{90-93}$ It has been emphasized that effective coaching employs a transactional and transformational leadership style, which is learner focused, providing direction and support to the coachee. ${ }^{40,50,51}$ Development of critical thinking is crucial for coaches. Allowing coaches to individualize techniques specific to situational and 
learner contexts has been described as the coach accessing a processual toolbox. ${ }^{90}$ In order to develop this situational awareness, coaches must have an understanding of the learner needs and educational context of that learner. This type of understanding can only be developed through clear communication.

This communication should confirm the coachee appreciates that learner development and achievement are the ultimate goals of the coach. There are two types of coaching in medical education, longitudinal and short term. In longitudinal coaching programs, this relationship is forged over time. Some medical education coaching programs have employed a coach who is a specialist in an area other than that of the coachee, to emphasize this enterprise as formative rather than summative in nature. Short term or coaching in the moment ${ }^{69}$ interactions of a single clinic or rotation lack these longitudinal and multi-disciplinary relationships. Here, establishing a positive environment falls to the communicative ability of the coach.

Explicit recommendations for creating this connection with the learner are not available, as each coach-learner relationship is different. Telio et al $^{94}$ describe establishing an educational alliance with the student and found effective solutions include discussing unity of goals, agreement on how to reach the goals and opening a dialogue which indicates commitment from each to the relationship. A learner will question faculty commitment to the relationship very early in the interaction, so authentic interest shown from faculty to student can be critical. ${ }^{94}$

Using a consistent tool can help both the learner and faculty adapt to the coaching paradigm and may simplify communicating the expectations of the coaching interaction for both parties. When both are aware of the instrument being used, the expectation of coaching will exist. An environment supportive of coaching observation and feedback may develop and become part of the institutional culture. Use of a tool for coaching has been present since the publication of the early coaching models. ${ }^{90}$ By employing the same framework for every interaction, the faculty should become more experienced with coaching techniques and may engage in deliberate practice each time the schematic is used. This idea is supported by psychology literature, summarized as follows: "intellectual activities, schema acquisition and automation are the primary mechanisms of learning." ${ }^{87}$ This is also supported in medical education literature. The Stanford Pediatric Residency Coaching program used tools for structured clinical observations developed by a coach and the program director. These were employed for every encounter and facilitated direct observation, reflection, feedback and goal setting. ${ }^{24}$ Criticism of the utility of models and schemas exists, stating that these scaffolds oversimplify the complexity inherent in the coaching dynamic. ${ }^{90}$ Arguably, a tool is useful for novice development and may be abandoned once coaches have sufficient practice and experience in the coaching role.

Proposed schema for coaching have included the RXOCD model described in January 2018 by the Royal College coaching webinar. ${ }^{69}$ The steps of RXOCD are rapport, expectations, observe, conversation and document. A second previously described model is the $\mathrm{R} 2 \mathrm{C} 2,{ }^{4}$ composed of relationship building, exploring reactions to feedback, understanding feedback content and coaching for performance change. These models may each facilitate delivery of coaching content. R2C2 has been validated in practice as a method of feedback delivery however, facilitators had difficulty with the concept of coaching for performance change. This indicates that this step may require further breakdown and instruction in this model. RXOCD is a framework specifically useful for EPA assessment, but lacks opportunity for reflection by the learner, goal setting and practice. Any model of coaching should include relationship engagement, self-direction from student, observation, providing the learner with explicit instruction or guidance and further goal setting and practice.

It is important for faculty coaches to remember that they need to guide the learner to retain the clinical teaching so that there is continued development after the coaching session itself. ${ }^{90}$ In order for a learner to continue to develop in the coach's absence, the learner must reflect on and internalize teaching received. This reflection is essential for the development of professional competence. ${ }^{91,95}$ The utility of reflection in coaching has been documented in the medical education literature. Reflection via portfolio use combined with individual coaching on student reflective entries, lead to improved self-awareness, insight and goal setting by coachees. ${ }^{20}$ The importance of reflection for recognizing learning moments, internalizing teaching and facilitating discussion of learning was demonstrated via use of a smartphone app in a workplace-based experiment. ${ }^{96}$ Together, coaching and reflection through the app significantly improved learner progress and goal setting, with increased motivation to engage in follow-up 
activities to increase clinical competence. ${ }^{96}$ Coaches must be aware of the importance of fostering reflection, student development and goal setting.

Teaching for novice coaches should emphasize clear communication, establishing a relationship with the learner, ${ }^{88,90}$ foster reflection, ${ }^{20,95}$ engage in critical thinking and employ a procedural toolbox to aid with coaching instruction. ${ }^{90}$ As novice coaches, tools or schemas may be useful to ensure comfort with initial role adoption. ${ }^{4}$

\section{Continuing professional development for faculty coaches: coaching the coach} Evidence and identified gaps

"The coaching philosophy adheres to the notion that learning is never finished and to reach one's maximum potential requires an external viewpoint to correct or enhance performance." ${ }^{29}$ This requirement of an external viewpoint to "correct or enhance performance" not only exists for medical learners but for faculty as well.

The paucity of feedback for practicing physicians was noted by Gawande ${ }^{23}$ who sought a coach to observe his surgical practice to assist him in increasing his skill.

Literature on self-assessment indicates that an individual's ability to identify gaps in his/her own performance is poor. ${ }^{97}$ It is expected that external assessment, feedback and instruction will benefit learners at any stage in their careers. This has been demonstrated in educational experiments. In one instance, surgeons with varying levels of expertise were filmed performing the same operation. Follow-up review of the video with a coach revealed that regardless of surgical level of experience, the coach was able to aid with problem resolution. The authors concluded the use of coaching was useful as a continuing professional development activity for surgeons. ${ }^{98}$ Similarly, in an experiment on the utility of multisource feedback, "physicians receiving multisource feedback found reflection beneficial and empowering, even many months after the feedback had been received." 4 Yet currently, the expectation for CPD is that faculty will self-assess, "practitioners will need to develop the expertise to systematically examine their own clinical performance data... and develop a plan to address areas of concern." 99 As this selfassessment approach is unlikely to succeed, use of an external observer with feedback and direct instruction for faculty would be invaluable to develop CBME associated skills, including development in the role of coach.
One method of enabling coaches to facilitate novel skill acquisition could be through utilizing the whole-partwhole learning model. In this model, the first "whole" is the introduction of the entire concept to the learner (faculty as coach). This is broken into parts (observation, specific instruction, goal setting) and then relinking these parts, reforming the whole in a more deeply meaningful way. ${ }^{58}$ Coaching can be completed in educational practice or via simulation on any of these component parts, allowing faculty to acquire further expertise in a desired aspect of coaching. This whole-part-whole model is in keeping with EPA and milestone achievements seen in CBME.

It has recently been suggested that CPD itself become competency-based, with ongoing demonstration of competencies with external data and feedback from colleagues for maintenance of certification with regulatory bodies. ${ }^{99,100}$ Faculty would be evaluated for competence in their individual practice area, and these evaluations would be used toward maintenance of certification credits. For those who are practicing in medical education, it is reasonable to expect that one such competency may be delivery of feedback or coaching skill. Established competencies for faculty CPD have not yet been described. Development of opportunities for learning, practice of coaching skills and development of assessment models in this domain may be required as CPD and maintenance of certification evolve to include competency assessment.

There is little literature available on coaching for educators. Coaching for improved teaching skill has been successfully reported in a small study using fourth-year medical students. Students received coaching feedback on video-taped teaching skills, with statistically significant improvement in self-rating, coach rating and blind reviewer rating, on a second post-coaching performance video. ${ }^{101}$ Another study reported emergency department faculty given coaching on the workplace-based assessments they documented for trainees; only those who engaged in deliberate practice post-coaching demonstrated significant improvement in feedback skills. ${ }^{102}$ In a longitudinal study on urban literacy coaches, a coach community of practice was created. Coaches could meet and discuss coaching issues, problem solve and receive support around how to coach. This was reported as beneficial by participants. ${ }^{103}$ Exploration of peer coaching in the literature has identified it as promising for continuing professional development activities with successful outcomes in areas of teaching excellence, reflection, and 
performance. ${ }^{104-109}$ In a scoping review of peer-coaching in health professions education, peer coaching was successful in increasing transfer of learned skills, although it had significant time and commitment requirements. ${ }^{29}$ The relationship between peers must be voluntary and based on mutual respect in order to promote acceptance of coaching feedback. ${ }^{4}$ Potential challenges to peer coaching implementation include perceived challenge of competence and autonomy. ${ }^{110}$

As CPD for faculty coaches develops, it is essential to note that the role of the coach changes across career stages. Newly qualified faculty will lack expertise as colleague coaches in some domains, those at mid- or end of career will have experience as instructors, administrators and medical experts to draw on for collegial coaching, and are more likely to assume leadership roles within academic communities. Following retirement, medical faculty may be sought for feedback on medical practice and are likely to assume the role of respected advisor.

\section{Faculty development coaching model: $\mathrm{COACH} 2 \mathrm{COACH}$}

Currently, professional development coaching is offered to faculty at some Canadian universities. ${ }^{70,71,111}$ These coaches are not focused on educational skill development. Instead, they offer general professional skills development in areas such as strategic planning, goal setting or problem-solving. Coaching for faculty coaches is relatively novel. Conceptually, it should follow principles of adult learning, employ reflection, goal setting and instructional feedback to improve coaching outcomes. Coaching of faculty differs from coaching of students primarily in that faculty coaching will address skill enhancement and increased performance of known or learned skills, whereas coaching of students will typically involve skill development of tasks in which learners are naïve and may include direct involvement of key stakeholders. ${ }^{112}$ Coaching of faculty coaches assumes the format of collegial discussion; it is not limited to workplace assessment and does not necessarily encompass medical knowledge. Faculty coaches, particularly with longitudinal coaching practice, will be domain experts in their own right and help in establishing an environment of mutual respect. To this end, a conceptual model for coaching faculty coaches to ameliorate coaching practices and achieve expertise has been developed by the authors.
The proposed model, COACH2COACH (Figure 1), is cyclical in nature and can be used continuously by faculty coaches. In this model, two colleagues, each an expert in his or her own right, collaborate to set goals, receive feedback on their coaching activities and continue to improve in coaching skill. Key to this collaborative effort is mutual respect and a desire for feedback. A COACH2COACH cycle begins with this collaboration. One faculty member performs a coaching activity, which is either directly observed or is recorded (ie, video, audio or written in a post encounter log). Recordings are adaptable to the privacy requested by the coachee subject. If not directly observed, the recorded coaching activity is viewed by both faculty collaborators simultaneously. This observation results in an informal assessment wherein some aspect of the coaching performance is examined and feedback is provided. To cultivate novel coaching skills, faculty recipients must reflect on their own behaviors and goals and incorporate deliberate practice of recommended behaviors. Finally, they habituate through the ongoing assimilation of the feedback into coaching practice. The cycle is repeated for the second member of the collaboration. This model needs to be validated by use with clinical faculty. It is conceptual in nature and based on available evidence. It adheres to principles of both adult learning theory and social cognitive theory, increasing the likelihood of acceptability to advanced adult learners. It allows feedback, reflection and deliberate practice for continuing professional development in the coaching domain and could be applied to additional aspects of practice.

\section{Discussion}

The efficacy of coaching has been well documented. ${ }^{43,44,47}$ With the paradigm shift to CBME medical faculty are facing a paradigm shift of their own, transforming from a well-known role of assessor to a novel role of coach. Coaching is a deliberate sequence of goal setting, observation, assessment and communication with specific guidance or instruction for skill acquisition. Coaching is especially suited to CBME as goal setting through EPA identification, observation through workplace-based assessment and feedback for performance change are all inherent in the CBME model. ${ }^{2}$ Coaching in medical education is a collaborative relationship between coach and coachee. The need for faculty development for this role 


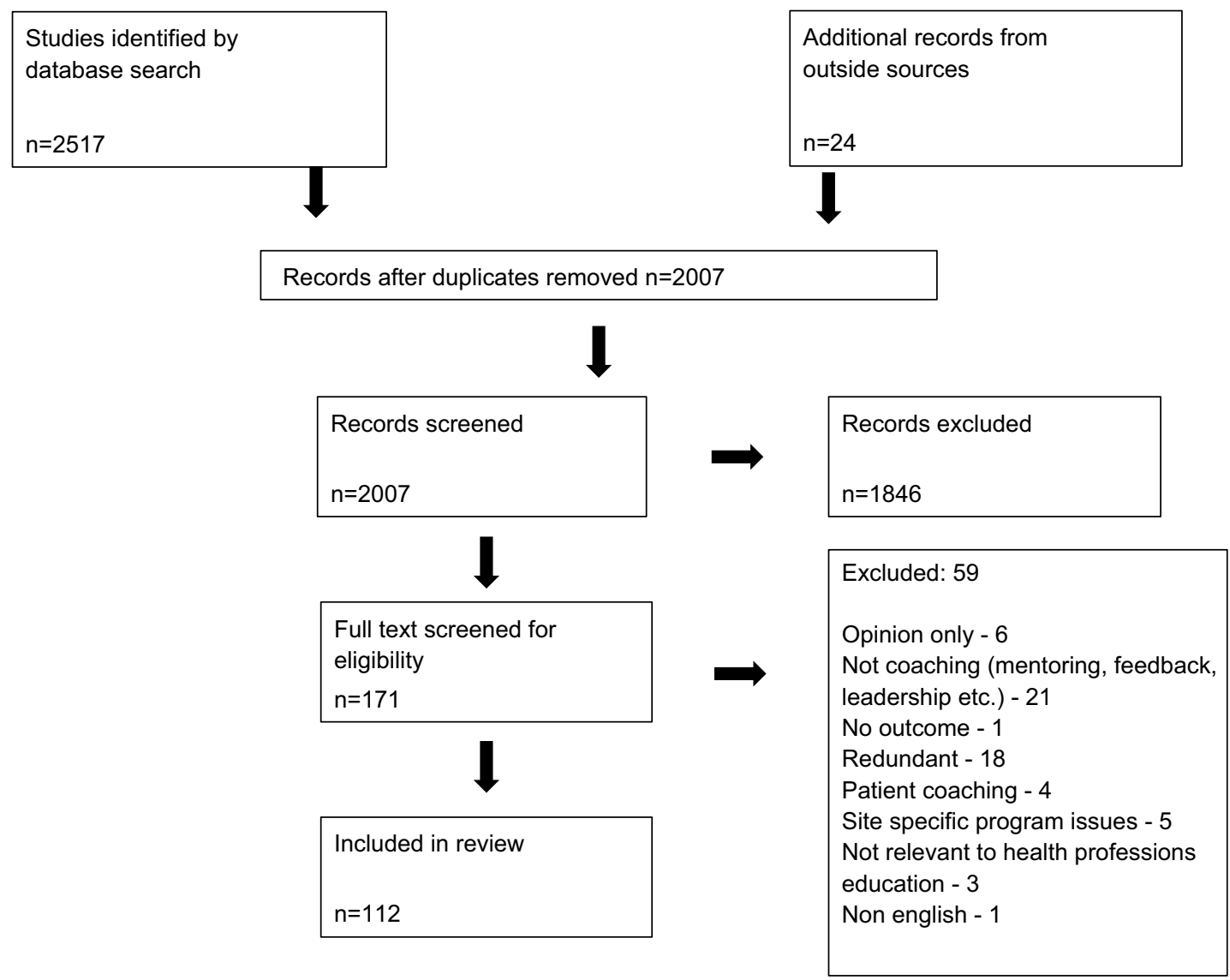

Figure I PRISMA diagram. Scoping review of coaching and faculty development. All searches concluded on March I2, 2018.

adoption is clear, although the best approach to faculty development in this area has not been described. Identified needs have included improved learner-teacher relationships, leading meaningful conversations and identifying factors which influence learner reception and acceptance of feedback. ${ }^{19}$ To date, the literature has been supportive of coaching in medical education with positive outcomes in areas of decisionmaking, reflective practice, technical skill acquisition, well-being and resilience. ${ }^{33}$ Due to the large number of university faculty in medicine, available resources may be insufficient to meet current needs. Local universities and programs will require further program development to train faculty coaches. The proposed strategies for faculty development adhere to ideas of deliberate practice, adult learning theory, self-determination theory and social cognitive theory. It is proposed that introducing coaching and CBME themes during existing learning activities may gradually lead to a culture of acceptance and may impact faculty motivation to participate in mandated curricular change. There are opportunities in education technology apps, creation of a living library and cognitive apprenticeship for learning coaching skills. Coaching behavior is inclusive of transactional and transformational leadership, creates an education alliance with the student, ${ }^{94}$ has clear communication, ${ }^{90}$ fosters student reflection ${ }^{95}$ and may employ the use of schema ${ }^{2,4}$

The growth of faculty coaches will continue throughout their careers, moving them from novice coach to expert advisor. In this way professional development is continual. A proposed model for colleague to colleague coaching, $\mathrm{COACH} 2 \mathrm{COACH}$ is presented.

\section{Conclusion}

As national curricula are transitioning to CBME, faculty development for coaching, a novel role in medical education, is required. Content for coaching development and evidence-based formation of faculty development activities are suggested. Ongoing feedback and skill development for faculty coaches is necessary. An 


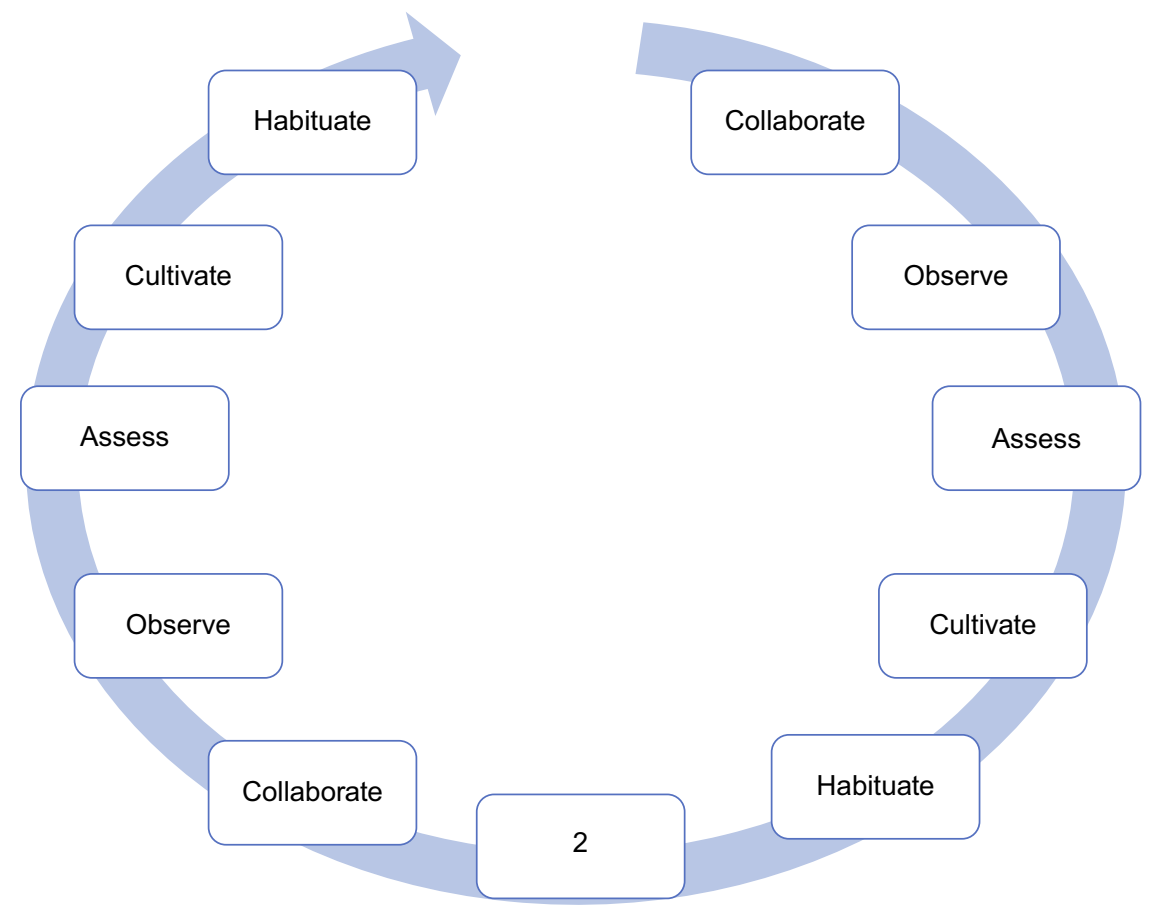

Figure $2 \mathrm{COACH} 2 \mathrm{COACH}$ model for faculty development in coaching. This cyclic model can be used in faculty development training sessions or in a self-directed fashion with a colleague to improve coaching skills. In the $\mathrm{COACH} 2 \mathrm{COACH}$ model, two faculty members Collaborate, each an expert in his or her own domain. To start, one faculty member completes a coaching session which is recorded and is then Observed by both the faculty member and the colleague coach. The colleague completes an Assessment and provides feedback. Thereafter, the new skill is Cultivated through deliberate practice and eventually becomes a Habitual part of routine coaching. The "2" represents 2 coaches involved in this process and also represents the repetition of the cycle for each coach, coaching between coaches one to the other, and giving coaching (coach) to get coaching, coach to coach. A cycle is complete when each coaching colleague has undergone Collaboration, Observation, Assessment, Cultivation and Habituation of coaching skills.

original conceptual model for coaching the coach, $\mathrm{COACH} 2 \mathrm{COACH}$, is proposed using principles of effective coaching and peer feedback to address the gap in continuing professional development for faculty coaches.

\section{Key points summary}

- Coaching can be an effective educational strategy, with evidence for improved performance, wellbeing, self-regulation, self-efficacy, resilience and goal attainment.

- Coaching is encouraged in novel CBME curricula and is aligned with task-specific EPA achievement.

- The role of coach is often collaborative with a focus on goal setting, developing solutions, goal attainment, development of learner-centric novel approaches, with increased self-awareness and personal responsibility of the coachee.
- Faculty development in coaching is necessary, as faculty members have reported being unfamiliar with a coaching role.

- Coaching may be a useful strategy to employ for faculty development.

- Faculty development activities should offer the opportunity for deliberate practice of coaching skills, provide a sense of relatedness, contain learner-driven content, increase learner motivation, and self-efficacy supporting behavior change.

- Development of opportunities for learning, practice of coaching skills and development of assessment models in this domain may be required as CPD and maintenance of certification evolves to include competency assessment.

- Although online materials and schemas exist to guide faculty in coaching activities, there is little feedback available to aid with faculty coach development. 
- A conceptual model for coaching faculty coaches to develop coaching skill and achieve expertise has been developed by the authors.

- The proposed model, $\mathrm{COACH} 2 \mathrm{COACH}$ (Figure 2), is cyclical in nature and can be used continuously by faculty coaches who seek external feedback on his or her own coaching practice. In this model, two colleagues, each an expert in his or her own right, collaborate to set goals, receive feedback on their coaching activities and continue to improve in coaching skill.

\section{Acknowledgment}

The authors thank Dr Bradley Petrisor, Department of Surgery, McMaster University, Hamilton ON.

\section{Disclosure}

The authors report no conflicts of interest in this work.

\section{References}

1. Lieff SJ. Faculty development: yesterday, today and tomorrow: guide supplement 33.2- Viewpoint. Med Teach. 2010;32 (5):429-431. doi:10.3109/01421591003677905

2. The Royal College of Physicians and Surgeons of Canada Website. Competence by design. 2018. Available from: http://www.royalcol lege.ca/rcsite/cbd/competence-by-design-cbd-e. Accessed February 6, 2018.

3. Richardson D. Prepare Clinical Teachers to Observe, Coach and Document. Royal College of Physicians and Surgeons of Canada Website; 2017. Available from: http://www.royalcollege.ca/rcsite/ documents/cbd/full-meantime-guide-e\#teachers. Accessed February 6, 2018.

4. Sargeant J, Lockyer J, Mann K, et al. Facilitated reflective performance feedback: developing an evidence- and theory-based model that builds relationship, explores reactions and content, and coaches for performance change (R2C2). Acad Med. 2015;90:1698-1706. doi:10.1097/ACM.0000000000000809

5. Barber K, Ed. The Canadian Oxford Dictionary. Toronto: Oxford University Press Canada; 1998.

6. LeBlanc C, Sherbino J. Coaching in emergency medicine. Cjem. 2010;12(6):520-524

7. Janes WC, Silvey D, Dubrowski A. Are educators actually coaches? The implication of teaching and learning via simulation in education in healthcare professions. Cureus. 2016;8(8):e734.

8. Sargent J, Bruce D, Campbell C. Practicing physicians needs for assessment and feedback as part of professional development. $J$ Continuing Edu Health Professions. 2013;33(1):S54-S62. doi: $10.1002 /$ chp. 21202

9. Holmboe ES. Realizing the promise of competency-based medical education. Acad Med. 2015;90(4):411-413. doi:10.1097/ ACM.0000000000000515

10. Holmboe ES, Ward DS, Reznick RK, et al. Faculty development in assessment: the missing link in competency-based medical education. Acad Med. 2011;86(4):460-467. doi:10.1097/ ACM.0b013e31820cb2a7

11. Griewatz J, Simon M, Lammerding-Koeppel M. Competency-based teacher training: A systematic revision of a proven programme in medical didactics. GMS J Med Educ. 2017;34(4):Doc44.
12. Lockyer J, Carraccio C, Chan MK, et al.; ICBME Collaborators. Core principles of assessment in competency-based medical education. Med Teach. 2017;39(6):609-616. doi:10.1080/ 0142159X.2017.1315082

13. Hawkins RE, Welcher CM, Holmboe ES, et al. Implementation of competency-based medical education: are we addressing concerns and challenges? Med Educ. 2015;49(11):1086-1102. doi:10.1111/ medu. 12831

14. Dath D, Ibost W. The importance of faculty development in the transition to competency based medical education. Med Teach. 2010;32(8):683-686. doi:10.3109/0142159X.2010.500710

15. Steinhert Y, Naismith L, Mann K. Faculty development initiatives designed to promote leadership in medical education. A BEME systematic review: BEME guide no.19. Med Teach. 2012;34 (6):483-503. doi:10.3109/0142159X.2012.680937

16. Tannenbaum E, Caccia N, Dore S, Sagle M, Kent N. P-OBS-JM -135 needs assessment of obstetrics and gynaecology faculty to inform faculty development priorities in the transition to competency based medical education (CBME). J Obstetrics Gynecol Can. 2017;39(5):404. doi:10.1016/j.jogc.2017.03.075

17. Desanghere L, Saxena A, Okunola O, Bonnycastle D, Olatunbosun F. Resident and faculty perspectives on effective clinical teaching. J Grad Med Educ. 2014;041.

18. Schultz K, Griffiths J. Implementing competency-based medical education in a postgraduate family medicine residency training program: A stepwise approach, facilitating factors, and processes or steps that would have been helpful. Acad Med. 2016;91 (5):685-689. doi:10.1097/ACM.0000000000001066

19. Favreau M, Tewksbury L, Lupi C, Cutrer W, Jokela J, Yarris L. Constructing a shared mental model for faculty development for the core entrustable professional activities for entering residency. Acad Med. 2017;92(6):759-764. doi:10.1097/ACM.000000000001511

20. Kopechek J, Bardales C, Lash AT, Walker C, Pfeil S, Ledord CH. Coaching the coach: A program for development of faculty portfolio coaches. Teach Learn Med. 2017;29(3):326-336. doi:10.1080/ 10401334.2016.1273781

21. Alken A, Luursema JM, Weenk M, Yauw S, Fluit C, van Goor H. Integrating technical and non-technical skills coaching in an acute trauma surgery team training: is it too much? Am J Surg. 2018;216 (2):369-374. doi:10.1016/j.amjsurg.2017.08.011

22. Deiorio NM, Carney PA, Kahl LE, Juve AM. Coaching: a new model for academic and career achievement. Med Educ Online. 2016;21(1):1087-2981. doi:10.3402/meo.v21.33480

23. Gawande A (2011, October 3). Personal best. The New Yorker. Available from: http://www.newyorker.com/magazine/2011/10/03/ personal-best. [Accessed July 11, 2016].

24. Rassebach CE, Blankenburg R. A novel pediatric residency coaching program: outcomes after one year. Acad Med. 2018;93(3):430434.

25. Buis C, Eckenhausen M, Cate O. Processing multisource feedback during residency under the guidance of a non-medical coach. Int J Med Educ. 2018;9:48-54. doi:10.5116/ijme.5a7f.169d

26. Watling C, Driessen E, van der Vleuten CPM, Lingard L. Learning culture and feedback: an international study of medical athletes and musicians. Med Educ. 2014;48:713-723. doi:10.1111/medu.12407

27. Czajkowski Z. Coach's work, knowledge, skills and personality. Stud Phys Culture Tourism. 2010;17(2):131-137.

28. Brown LE, Rangachari D, Melia M. Beyond the sandwich from feedback to clinical coaching for residents as teachers. MedEdPORTAL. 2017;13:10627. doi:10.15766/mep_2374-8265.10603

29. Schwellnus H, Carnahan H. Peer coaching with health care professionals: what is the current status of the literature and what are the key components necessary in peer coaching? A scoping review. Med Teach. 2014;36(1):38-46. doi:10.3109/0142159X.2013.836269

30. Abiddin NZ. Mentoring and coaching the roles and practices. J Human Res Adult Learn. 2007;107-116. 
31. Thorn PM, Raj JM. A culture of coaching: achieving peak performance of individuals and teams in academic health centers. Acad Med. 2012;87(11):1482-1483. doi:10.1097/ACM.0b013e31826ce3bc

32. Losch S, Traut-Mattausch E, Muhlberger M, Jonas E. Comparing the effectiveness of individual coaching, self-coaching, and group training: how leadership makes the difference. Front Psychol. 2016;7(629):1-17. doi:10.3389/fpsyg.2016.00001

33. Lovell B. What do we know about coaching in medical education? A literature review. In: Medical Education in Review. 2017:1-15.

34. Ohio University Website (n.d.) 3 styles of sports coaching. Available from: https://onlinemasters.ohio.edu/3-styles-of-sportscoaching/. Accessed January 30, 2018.

35. Schmidt R, Lee T. Motor control and learning 5th edition; A behavioural emphasis. 2011. Available from: http://www.human kinetics.com/products/all-products/Motor-Control-and-Learning -5th-Edition-eBook. Accessed February 2, 2018.

36. Wulf G, Shea C, Lewthwaite R. Motor skill learning and performance: a review of influential factors. Med Educ. 2009;44 (1):75-84. doi:10.1111/j.1365-2923.2009.03421.x

37. Gallimore R, Tharp R. What a coach can teach a teacher, 1975-2004: reflections and reanalysis on John Wooden's teaching practices. Sport Psychologist. 2004;18:119-137. doi:10.1123/ tsp.18.2.119

38. Von Bergen CW, Bressler MS, Campbell K. The sandwich feedback method: not very tasty. J Behav Stud Bus. 2014;7:1-13.

39. Tanaka P, Bereknyei MS, Walker K, et al. Implementation of a needs-based, online feedback tool for anesthesia residents with subsequent mapping of the feedback to the ACGME milestones. Anesth Analg. 2017;124(2):627-635. doi:10.1213/ ANE.0000000000001647

40. Muhlberger M, Traut-Mattausch E. Leading to effectiveness: comparing dyadic coaching and group coaching. J Appl Behav Sci. 2015;51(2):198-230. doi:10.1177/0021886315574331

41. Bass B. From translational to transformational leadership: learning to share the vision. Organ Dyn. 1990;18(3):19-31. Available from: http://discoverthought.com/Leadership/References_files/Bass\% 20leadership\%201990.pdf.

42. Grover S, Furnham A. Coaching as a developmental intervention in organisations: a systematic review of its effectiveness and the mechanisms underlying it. PLoS One. 2016;11(7):1-41. doi:10.1371/journal.pone.0159137

43. Theeboom T, Beersma B, van Vianen A. Does coaching work? A meta-analysis on the effects of coaching on individual level outcomes in an organizational context. J Positive Psychol. 2014;9 (1):1-18. doi:10.1080/17439760.2013.837499

44. Gazelle G, Liebschutz JM, Riess H. Physician burnout: coaching a way out. J Gen Intern Med. 2015;30(4):508-513. doi:10.1007/ s11606-014-3144-y

45. Palamara K, Kauffman C, Stone V, Bazari H, Donelan K. Promoting success: A professional development coaching program for interns in medicine. J Grad Med Educ. 2015;7(4):630-637. doi:10.4300/JGME-D-14-00791.1

46. Westcott L. How coaching can play a key role in the development of nurse managers. J Clin Nurs. 2016;25(17-18):2669-2677. doi:10.1111/jocn.13315

47. Grant A, Curtayne L, Burton G. Executive coaching enhances goal attainment, resilience and workplace well-being: a randomized controlled study. J Positive Psychol. 2009;4(5):396-407. doi:10.1080/ 17439760902992456

48. De Meuse K, Dai G, Lee R. Evaluating the effectiveness of executive coaching; Beyond ROI? Coaching Int J Theory Res Pract. 2009;2(2):117-134. doi:10.1080/17521880902882413

49. Bar-Haim S, Harries N, Nammourah I, et al.; MERC project. Effectiveness of motor learning coaching in children with cerebral palsy: A randomized controlled trial. Clin Rehabil. 2010;11:1009-1020. doi:10.1177/0269215510371428
50. Rowold J. Transformational and transactional leadership in martial arts. J Appl Sport Psychol. 2006;18(4):312-325. doi:10.1080/ 10413200600944082

51. Hampson R, Jowett S. Effects of coach leadership and coach-athlete relationship on collective efficacy. Scand J Med Sci Sports. 2014;24:454-460. doi:10.1111/sms.2014.24.issue-2

52. Cuda S, Doerr D, Gonzalez M. Using facilitators in mock codes: recasting the parts for success. J Contin Ed Nurs. 1999;30 (6):279-283.

53. Min H, Morales DR, Orgill D, Smink DS, Yule S. Systematic review of coaching to enhance surgeons' operative performance. Surgery. 2015;158(5):1168-1191. doi:10.1016/j.surg.2015.03.007

54. George P, Reis S, Nothnagle M. Using a learning coach to teach residents evidence-based medicine. Fam Med. 2012;44 (5):351-355.

55. Subramaniam A, Silong AD, Uli J, Ismail IA. Effects of coaching supervision, mentoring supervision and abusive supervision on talent development among trainee doctors in public hospitals: moderating role of clinical learning environment. BMC Med Educ. 2015;13:15:129. doi:10.1186/s12909-015-0407-1

56. Schofield SJ, Bradley S, Macrae C, Nathwani D, Dent J. How we encourage faculty development. Med Teach. 2010;32(11):883-886. doi:10.3109/0142159X.2010.506564

57. Engbers R, Fluit $C$, Bolhuis $S$, de Visser $M$, Laan R. Implementation of teaching policy in university teaching hospitals. Adv Health Sci Edu. 1999;22:985. doi:10.1007/s10459016-9737-y

58. Knowles M, Holton EF, Swanson R. The adult learner: the definitive classic in adult education and human resource development 8 th edition. 2014. Available from: https://www.amazon.com/AdultLearner-definitive-education-development-ebook/dp/ B00QMIEELK $/$ ref $=$ mt_kindle?_encoding $=\mathrm{UTF} 8 \& \mathrm{me}=$. Accessed February 2, 2018.

59. Cox CW, Gunderman RB. Androgogic approaches to continuing medical education. Acad Radiol. 2017;24(10):1325-1326. doi:10.1016/j.acra.2017.05.004

60. Schumacher DJ, Englander R, Carraccio C. Developing the master learner: applying learning theory to the learner, the teacher, and the learning environment. Acad Med. 2013;88(11):1635-1645. doi:10.1097/ACM.0b013e3182a6e8f8

61. Nagler A, Andolsek K, Rudd M, Kuhn C. Providing successful faculty development to graduate medical education program directors. Int J Med Edu. 2017;8:324-325. doi:10.5116/ijme.59a9.73cc

62. Steinhert Y, Mann K, Centeno A, et al. A systematic review of faculty development initiatives designed to improve teaching effectiveness in medical education: BEME guide no. 8. Med Teach. 2006;28(6):497-526. doi:10.1080/01421590600902976

63. Moore P, Montero L, Trivino X, Sirhan M, Leiva L. Impact beyond the objectives: A qualitative study of a faculty development program in medical education. Revista Medica Chile. 2014;142 (3):336-343. doi:10.4067/S0034-98872014000300008

64. Kotter International Website. 8-step process for leading change. 2017. Available from: https://www.kotterinc.com/8-steps-processfor-leading-change/. Accessed February 8, 2018.

65. Ericsson KA, Krampe RT, Tesch-Romer C. The role of deliberate practice in the acquisition of expert performance. Psychol Rev. 1993;100(3):363-406. doi:10.1037/0033-295X.100.3.363

66. Kritsonis A. Comparison of change theories. Int J Scholarly Acad Intellectual Diversity. 2005;8(1):1-7.

67. Cane J, O'Connor D, Michie S. Validation of the theoretical domains framework for use in behaviour change and implementation research. Implementation Sci. 2012;7(37). doi:10.1186/17485908-7-37

68. Gifford KA, Fall LH. Doctor coach: a deliberate practice approach to teaching and learning clinical skills. Acad Med. 2014;89 (2):272-276. doi:10.1097/ACM.0000000000000097 
69. The Royal College of Physicians and Surgeons of Canada Website. (2018). CBD coaching model Webinar Jan 12- 18. Available from: http://www.kaltura.com/index.php/extwidget/preview/partner_id/ 1688662/uiconf_id/22517242/entry_id/1_godwxuzo/embed/auto? Accessed January 12, 2018.

70. McMaster University Continuing Health Science Education website. CHSE coaching. n.d.. Available from: https://fhs.mcmaster.ca/ facdev/CBME.html. Accessed January 15, 2018.

71. University of British Columbia Faculty of Medicine Website. Coaching. Available from: https://mednet.med.ubc.ca/HR/ managingFaculty/CareerAndProfessionalDevelopment/Pages/ Coaching.aspx. Accessed January 15, 2018.

72. University of Ottawa: Faculty of Medicine: Continuing Professional Development Website. Coach orientation to the portfolio on core competencies (ePortfolio). 2018. Available from: https://learn.med.uottawa.ca/courses/eportfolio-orientation/. Accessed January 15, 2018.

73. University of Toronto: MD Program: Office of Faculty Development Website. Coaching for performance enhancement academy scholars and progress reviews. 2018. Available from: http://ofd.med.utoronto.ca/resources. Accessed January 15, 2018.

74. The Association of Faculties of Medicine of Canada Website. The AFMC 2017 annual report. 2017. Available from: https://www. afmc.ca/. Accessed January 15, 2018.

75. Lawler PA, King KP. Planning for Effective Faculty Development: Using Adult Learning Strategies. Professional Practices in Adult Education and Human Resource Development Series. Malabar (FL): Krieger Publishing Company; 2000.

76. Cabrera D, Roland D. How do we structure knowledge? Enter the rhizome. [blog post]. 2014. Available from: https://icenetblog.royal college.ca/2014/12/02/how-do-we-structure-knowledge-enter-therhizome/. Accessed January 30, 2018.

77. Life in the Fastlane. FOAM [blogpost]. August 29, 2017. Available from: https://lifeinthefastlane.com/foam/. Accessed January 5, 2018

78. Ladhani Z, Chhatwal J, Vyas R, Iqbal M, Tan C, Diserens D. Online role playing for faculty development. Clin Teach. 2011;8 (1):31-36. doi:10.1111/j.1743-498X.2010.00401.x

79. Foucault ML, Vachon B, Thomas A, Rochette A, Giguere CE. Utilization of an electronic portfolio to engage rehabilitation professionals in continuing professional development: results of a provincial survey. Disabil Rehabil. 2018;40(13):1591-1599. doi:10.1080/09638288.2017.1300335

80. Buckley S, Coleman J, Davison I, et al. The educational effects of portfolios on undergraduate student learning: a Best Evidence Medical Education (BEME) systematic review. BEME Guide No. 11 Med Teach. 2009;31(4):282-298. doi:10.1080/01421590902889897

81. Barry M, Kuijer-Siebelink W, Nieuwenhuis L, Scherpbier-de Haan N. Communties of practice: A means to support occupational therapists continuing professional development. A literature review. Aust Occup Ther J. 2017;64(2):185-193. doi:10.1111/14401630.12334

82. Boursicot K, Etheridge L, Ker J, et al. (2010). Ottawa 2010 performance assessment theme group report. Available from: http:/emmi lestones.pbworks.com/w/file/fetch/63926624/Miller. Accessed February 20, 2018.

83. Coaching Association of Canada website. Women in coaching Canada games apprenticeship program. 2018. Available from: https://www.coach.ca/-p157337. Accessed January 15, 2018.

84. Iyasere CA, Baggett M, Romano J, Jena A, Mills G, Hunt DP Beyond continuing medical education: clinical coaching as a tool for ongoing professional development. Acad Med. 2016;91:1647-1650. doi:10.1097/ACM.0000000000001131

85. Bariess R, Radley M (2010). Coaching via cognitive apprenticeship. SIGCSE: Proceedings of the 41st ACM technical symposium on Computer Science education. New York, NY: Association for Computer Machinery.
86. Malamed C. What Is Cognitive Load? The e-learning coach; 2016. Available from: http://theelearningcoach.com/learning/what-iscognitive-load/. Accessed January 15, 2018.

87. Sweller J. Cognitive load theory, learning difficulty, and instructional design. Learn Instruction. 1994;4(4):295-312. doi:10.1016/ 0959-4752(94)90003-5

88. Rogers W, Reade I, Hall C. Factors that influence coaches use of sound coaching practices. Int J Sports Sci Coach. 2007;2 (2):155-170. doi:10.1260/174795407781394284

89. Kopechek J, Khandelwal S, Grieco CA, Post DM, Davis JA, Ledford CH. Portfolio-associated faculty: A qualitative analysis of successful behaviors from the perspective of the student. J Biomed Edu. 2016;2016:1-7. doi:10.1155/2016/4602704

90. Cushion CJ, Armour KM, Jones RL. Locating the coaching process in practice: models 'for' and 'of' coaching. Phys Educ Sport Pedagogy. 2006;11(1):83-99. doi:10.1080/17408980500466995

91. Yoon M, El-Haddad C, Durning S, Hu W. Coaching early career educators in the health professions. Clin Teach. 2016;13 (4):251-256. doi: $10.1111 /$ tct. 12568

92. Graddy R, Wright S. Going the extra mile: lessons learned from running coaches applied to medicine. Educ Health (Abingdon). 2017;30(1):89-92. doi:10.4103/1357-6283.210498

93. Beasley HL, Ghousseini HN, Wiegmann DA, Brys NA, Pavuluri Quamme SR, Greenberg CC. Strategies for building peer coaching relationships. JAMA Surg. 2017;152(4):e165540. doi:10.1001/ jamasurg.2016.5540

94. Telio S, Ajjawi R, Regehr G. The 'educational alliance' as a framework for reconceptualizing feedback in medical education. Acad Med. 2015;90:609-614. doi:10.1097/ACM.0000000000000560

95. Mann K, Gordon J, Mcleod A. Reflection and reflective practice in health professions education: a systematic review. Adv Health Sci Edu. 2009;14:595. doi:10.1007/s10459-008-9141-3

96. Konings KD, van Berlo J, Koopmans R, et al. Using a smartphone app and coaching group sessions to promote residents' reflection in the workplace. Acad Med. 2016;91(3):365-370. doi:10.1097/ ACM.0000000000000989

97. Regehr G, Eva K. Self-assessment, self-direction and the self-regulating professional. Clin Orthopedics Related Res. 2006;449:34-38.

98. Hu YY, Peyre SE, Arriaga AF, et al. Postgame analysis: using video-based coaching for continuous professional development. $J \mathrm{Am}$ Coll Surg. 2012;214:115-124. doi:10.1016/j.jamcollsurg.2011.10.009

99. Lockyer J, Bursey F, Richardson D, et al. Competency-based medical education and continuing professional development: A conceptualization for change. Med Teach. 2017;39(6):617-622. doi:10.1080/0142159X.2017.1315064

100. Sargent J, Wong BM, Campbell CM. CPD of the future: a partnership between quality improvement and competency based education. Med Educ. 2018;1:125-135. doi:10.1111/ medu. 13407

101. Tchekmedyian V, Shields HM, Pelletier SR, Pazo VC. The effect of rubric-guided, focused, personalized coaching sessions and video-recorded presentations on teaching skills amoung fourth year medical students: A pilot study. Acad Med. 2017;92 (11):1583-1589. doi:10.1097/ACM.0000000000001686

102. Nichols D, Kulaga A, Ross S. Coaching the coaches. Med Educ. 2013;47:513-535. doi:10.1111/medu.12181

103. Woulfin S. Coach professional development in the urban emergent context. Urban Edu. 2017 June;1-30. doi:10.1177/ 0042085917714513

104. Cheng A, Grant V, Huffman J, et al. Coaching the debriefer: peer coaching to improve debriefing quality in simulation programs. Simul Healthc. 2017;12(5):319-325. doi:10.1097/SIH.0000000000000232

105. Sekerka LE, Chao J. Peer coaching as a technique to foster professional development in clinical ambulatory settings. $J$ Contin Educ Health Prof. 2003 Winter;23(1):30-37. doi:10.1002/chp.1340230106 
106. Garcia I, James RW, Bischof P, Baroffio A. Self-observation and peer feedback as a faculty development approach for problem-based learning tutors: a program evaluation. Teach Learn Med. 2017;29(3):313-325. doi:10.1080/10401334.2017.1279056

107. McLeod PJ, Steinert Y. Peer coaching as an approach to faculty development. Med Teach. 2009;31(12):1043-1044. doi:10.3109/ 01421590903188729

108. Inra JA, Pelletier S, Kumar NL, Barnes EL, Shields HM. An active learning curriculum improves fellows' knowledge and faculty teaching skills. Adv Med Educ Pract. 2017;26(8):359-364. doi:10.2147/AMEP.S135538

109. Becker KD, Damey D, Domitrovich C, Keperling JP, Lalongo NS. Supporting universal prevention programs: a two-phased coaching model. Clin Child Fam Psychol Rev. 2013;16(2):213-228.
110. Mutabdzic D, Mylopoulos M, Murnaghan ML, et al. Coaching surgeons: is culture limiting our ability to improve? Ann Surg. 2015;262(2):213-216. doi:10.1097/SLA.0000000000001247

111. Memorial University of Newfoundland Learning and Development website. Coaching. n.d.. Available from: http://www.mun.ca/hr/learn ing-development/courses/professional/coaching.php.

Accessed January 15,2018

112. Sachdeva AK. Continuing professional development in the twenty first century. $J$ Contin Educ Health Prof. 2016 Summer;36 Suppl 1(Suppl 1):SS8-SS1. doi:10.1097/ CEH.0000000000000107
Advances in Medical Education and Practice

\section{Publish your work in this journal}

Advances in Medical Education and Practice is an international, peerreviewed, open access journal that aims to present and publish research on Medical Education covering medical, dental, nursing and allied health care professional education. The journal covers undergraduate education, postgraduate training and continuing medical education

\section{Dovepress}

including emerging trends and innovative models linking education research, and health care services. The manuscript management system is completely online and includes a very quick and fair peer-review system. Visit http://www.dovepress.com/testimonials.php to read real quotes from published authors. 